\title{
Maternal Near-Miss: A Multicenter Surveillance in Kathmandu Valley
}

\author{
Ashma Rana, ${ }^{1}$ Gehanath Baral, ${ }^{2}$ Ganesh Dangal ${ }^{3}$ \\ 'Department of Obstetrics and Gynaecology, Tribhuwan University Teaching Hospital, ${ }^{2}$ Department of Obstetrics and \\ Gynaecology, Paropakar Maternity and Women's Hospital, ${ }^{3}$ Department of Obstetrics and Gynaecology, Kathmandu Model \\ Hospital, Kathmandu, Nepal.
}

Introduction: Multicenter surveillance has been carried out on maternal near-miss in the hospitals with sentinel units. Near-miss is recognized as the predictor of level of care and maternal death. Reducing Maternal Mortality Ratio is one of the challenges to achieve Millennium Development Goal. The objective was to determine the frequency and the nature of near-miss events and to analyze the near-miss morbidities among pregnant women.

Methods: A prospective surveillance was done for a year in 2012 at nine hospitals in Kathmandu valley. Cases eligible by definition were recorded as a census based on WHO near-miss guideline. Similar questionnaires and dummy tables were used to present the results by non-inferential statistics.

Results: Out of 157 cases identified with near-miss rate of 3.8 per 1000 live births, severe complications were postpartum hemorrhage $62(40 \%)$ and preeclampsia-eclampsia 25 (17\%). Blood transfusion 102 (65\%), ICU admission 85 (54\%) and surgery 53 (32\%) were common critical interventions. Oxytocin was main uterotonic used both prophylactically and therapeutically at health facilities. Total of $30(19 \%)$ cases arrived at health facility after delivery or abortion. $\mathrm{MgSO}_{4}$ was used in all cases of eclampsia. All laparotomies were performed within three hours of arrival. Near-miss to maternal death ratio was 6:1 and MMR was 62.

Conclusions: Study result yielded similar pattern amongst developing countries and same near-miss conditions as the causes of maternal death reported by national statistics. Process indicators qualified the recommended standard of care. The near-miss event could be used as a surrogate marker of maternal death and a window for system level intervention.

Keywords: abortion; eclampsia; hemorrhage; near-miss; surveillance.

\section{INTRODUCTION}

Maternal near-miss is a retrospective condition that refers to severe acute maternal morbidity in which a woman nearly died but survived a complication that occurred during pregnancy, childbirth or within 42 days of termination of pregnancy. ${ }^{1-6}$ Though there are no national data on near-miss, it would be quite high in comparison to developed countries' figure of 4-7 per 1000 deliveries and the pattern may also differ..$^{7-12}$ The near-miss data are the predictor of maternal mortality and once obstetric problems are clearly identified, remedial actions could be taken to reduce maternal death. ${ }^{13}$

Correspondence: Dr. Gehanath Baral, Department of Obstetrics and Gynaecology, Paropakar Maternity and Women's Hospital, Thapathali, Kathmandu, Nepal. Email: gehanath@gmail.com, Phone: +977-9841228829. 
Health service utilization rate has increased by three times in between national surveys of 1998 and 2008 but Postpartum Hemorrhage (PPH) $(24 \%)$ is still a main cause of maternal death. Currently we have high pregnancy related mortality ratio (247 deaths due to any causes in pregnancy up to six weeks after pregnancy event per 100 thousand live births) and maternal mortality ratio (229 deaths due to pregnancy and childbirth related cause per 100 thousand live births) which constitutes $11 \%$ of deaths of women of reproductive age group. ${ }^{7,14,15}$

\section{METHODS}

This was a multicenter prospective surveillance at nine hospitals in Kathmandu valley that have tertiary level facility for the care of pregnant women during a year in 2012. This study was designed to determine frequency and nature of near-miss events and analysis of near-miss morbidities among pregnant women with the assumption that would help to work towards reducing Maternal Mortality Ratio (MMR) and achieving Millennium Development Goal (MDG). Current study represented the concept of morbid continuum of maternal morbidity and mortality (Figure 1).

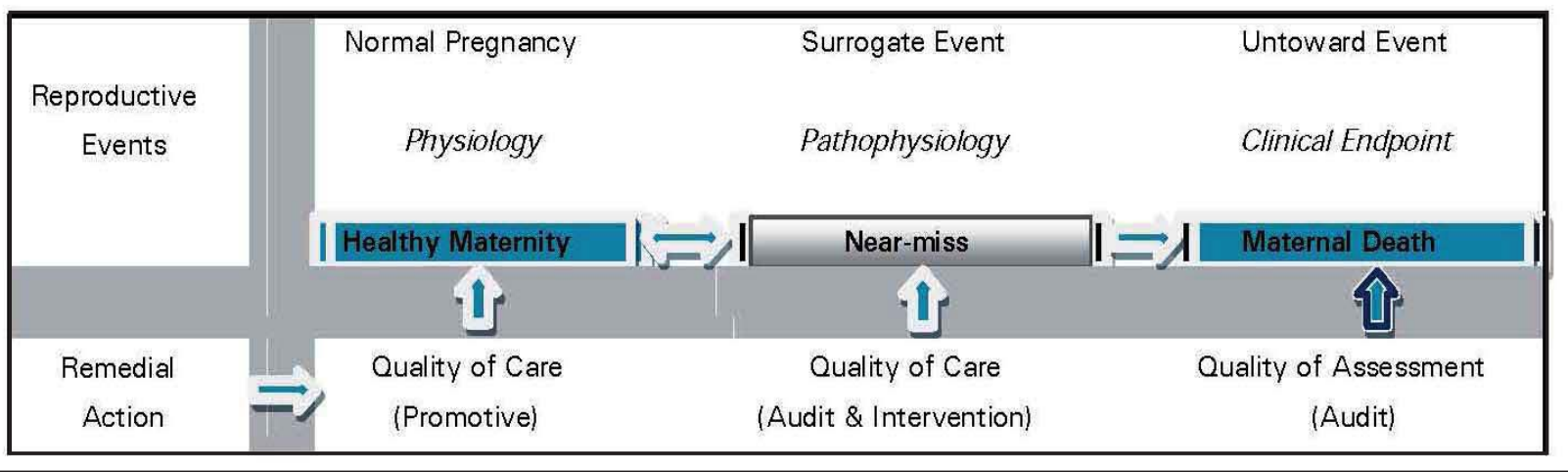

Figure 1. Conceptual framework.

Main study variables were preeclampsia, eclampsia, postpartum hemorrhage, severe infection and sepsis, uterine rupture, organ dysfunction, uterotonics, magnesium sulfate, obstetric complications, ectopic pregnancy, abortion, surgical intervention and timing of care. Operational case definitions were established from prior workshops based on WHO near-miss surveillance guideline. ${ }^{1,16}$ Individual pregnant women satisfying the case definition admitted at health facility were considered a study unit. In-patient record file was the source document and source data were verified with treating physicians. Data collection tool and the dummy tables for data compilation and analysis were adopted from the same guideline. Ethical approval was taken from Nepal Health Research Council and ethical committees from each participant institutions.

\section{RESULTS}

There were 41,676 total live births, 157 maternal nearmiss cases and 26 maternal deaths during a year of study in the 2012 at nine health care facilities with sentinel units. Census of eligible cases obtained in 2012 was 157 altogether. There was near-miss rate of 3.8 per 1000 live births against 62.4 per 100000 MMR yielding near-miss to death ratio of $6: 1$ (Table 1 ).

\begin{tabular}{|c|c|c|}
\hline $\begin{array}{l}\text { Maternal near-miss } \\
\text { indicators }\end{array}$ & Indices & Range \\
\hline Maternal Near-Miss, MNM & 157 & $6-46$ \\
\hline Maternal Death, MD & 26 & $0-9$ \\
\hline Live Birth, LB & 41676 & $618-21543$ \\
\hline $\begin{array}{l}\text { Severe Maternal } \\
\text { Outcome Rate, SMOR = } \\
(\mathrm{MNM}+\mathrm{MD}) / \mathrm{LB}\end{array}$ & $4.4 / 1000$ & $2-16$ \\
\hline $\begin{array}{l}\text { Near-Miss Rate, NMR = } \\
\text { MNM/LB }\end{array}$ & $3.8 / 1000$ & $1.4-16$ \\
\hline $\begin{array}{l}\text { Mortality Index, MI = MD/ } \\
(\mathrm{MNM}+\mathrm{MD})\end{array}$ & 0.142 & $0-0.45$ \\
\hline $\begin{array}{l}\text { Near-Miss per Maternal } \\
\text { Death, MNM : } 1 \text { MD }\end{array}$ & $6: 1$ & $0-12: 1$ \\
\hline $\begin{array}{l}\text { Maternal Mortality Ratio, } \\
\text { MMR }\end{array}$ & 62.4 & $0-200$ \\
\hline
\end{tabular}

The total clinical conditions satisfying operational definition during the study period were 157. Pregnancy ranged from 4-42 weeks $(n=140$, mean $=33.56$ and standard deviation $=8.88$ ). While describing clinical conditions each datum was not mutually exclusive as the certain conditions were in continuum of clinical progression. Commonly observed severe and potentially 
Rana et al. Maternal Near-Miss: A Multicenter Surveillance in Kathmandu Valley

life threatening conditions have been displayed in Table 2 and some less common conditions like severe anemia and ectopic pregnancy were included in other category. Majority $(75 \%, n=118)$ of the conditions were present either at arrival or up to 12 hours of arrival at facility.

Each of the critical interventions had to be offered to around $60 \%$ of cases within 12 hours of arrival. Around two-thirds had taken blood or blood product transfusion, more than half needed Intensive Care Unit (ICU) and one-third had surgical intervention (Table 3).

On an average $60 \%\left(1 / 3^{\text {rd }}\right.$ to $\left.3 / 4^{\text {th }}\right)$ cases with organ dysfunction were detected on arrival at health facility. Inclusive of multi-organ dysfunction, the most common systems involved were uterine, hematologic, cardiovascular, respiratory and neurological (Table 4).

\begin{tabular}{|lr|}
\hline $\begin{array}{l}\text { Table 2. Severe complication/ potentially life- } \\
\text { threatening conditions }(\mathbf{n}=\mathbf{1 5 7}, \mathbf{>} \mathbf{1} \text { condition in } \mathbf{7 \%}) .\end{array}$ \\
\hline Particulars & $\mathbf{n}(\%)$ \\
\hline Postpartum hemorrhage & $62(39.5 \%)$ \\
Preeclampsia-Eclampsia & $25(16 \%)$ \\
Infection & $12(7.6 \%)$ \\
Ruptured uterus & $9(6 \%)$ \\
Heart disease & $11(7 \%)$ \\
\hline
\end{tabular}

\begin{tabular}{|c|c|}
\hline Particulars & n (\%) \\
\hline Blood transfusion & $102(65 \%)$ \\
\hline Intensive care admission & $85(54 \%)$ \\
\hline Surgical intervention & $50(32 \%)$ \\
\hline Other (radiological) & $3(2 \%)$ \\
\hline
\end{tabular}

\begin{tabular}{|lr|}
\hline $\begin{array}{l}\text { Table 4. Organ dysfunction/life threatening conditions } \\
\text { ( } \mathbf{n = 1 5 7 ,}>\mathbf{1} \text { condition in } \mathbf{5 \%}) .\end{array}$ \\
\hline System & Frequency \\
Uterine & $42(27 \%)$ \\
Hematologic & $35(22 \%)$ \\
Cardiovascular & $33(21 \%)$ \\
Respiratory & $30(19 \%)$ \\
Neurological & $16(10 \%)$ \\
Renal & $6(4 \%)$ \\
Hepatic & $3(2 \%)$ \\
\hline
\end{tabular}

Out of 121 late pregnancy events only 36 (30\%) underwent vaginal delivery and rest had surgical intervention. There were nine laparotomies for ruptured uterus and six laparotomies for ectopic pregnancy, and only eight required uterine evacuation (Table 5). Out of total birth, there were $89(74 \%)$ live births and 10
$(11 \%)$ early Neonatal Deaths (NNDs). Process indicators have been displayed in (Table 6).

\begin{tabular}{|c|c|}
\hline \multicolumn{2}{|c|}{$\begin{array}{l}\text { Table } 5 \text {. Final mode of delivery/termination of pregnancy } \\
(n=141) \text {. }\end{array}$} \\
\hline Particulars & n (\%) \\
\hline Early Pregnancy Events & $14 \%(n=20)$ \\
\hline Abortion & $13(9 \%)$ \\
\hline $\begin{array}{l}\text { Laparotomy for Ectopic } \\
\text { Pregnancy }\end{array}$ & $6(4 \%)$ \\
\hline Other & $1(0.7 \%)$ \\
\hline Late Pregnancy Events & $86 \%(n=121)$ \\
\hline Vaginal Delivery & $36(26 \%)$ \\
\hline Caesarean Section & $76(54 \%)$ \\
\hline $\begin{array}{l}\text { Laparotomy for Ruptured } \\
\text { Uterus }\end{array}$ & $9(6 \%)$ \\
\hline \multicolumn{2}{|l|}{ Vital status of newborn } \\
\hline Live births & $\begin{array}{l}\mathrm{n}=89(74 \% \text { of } 121 \\
\text { births) }\end{array}$ \\
\hline Early NNDs & $\begin{array}{l}\mathrm{n}=10 \quad(11 \% \text { of } 89 \text { Live } \\
\text { births) }\end{array}$ \\
\hline
\end{tabular}

Table 6. Conditions at arrival in the facility and the referral process.

Particulars n (\%)

Delivery or abortion occurred before

arrival at any health facility

Delivery within 3 hours of arrival at the

health facility

$31(20 \%)$

Laparotomy within 3 hours of hospital

arrival or in other hospital

$18(12 \%)$

Woman referred from other health facility 42 (27\%)

Woman referred to higher facility hospital 16 (10\%)

Amongst 157 cases oxytocin ( $n=104,66 \%$ ) was the major uterotonic used to prevent postpartum hemorrhage followed by ergometrine, misoprostol and carboprost in $47(30 \%), 41(26 \%)$ and 31 (20\%) cases respectively. But 30 cases $(19 \%)$ arrived at facility after the delivery or abortion. Again for the medical treatment of postpartum hemorrhage (PPH), oxytocin was used in $92(59 \%)$ followed by misoprostol, ergometrine, carboprost and tranexamic acid in 55 (35\%), 47 (30\%), $43(27 \%)$ and $38(24 \%)$ cases respectively. Common modalities of surgical treatment were compression procedures like tamponade, packing or suture $(n=25$, $16 \%)$, hysterectomy ( $n=20,13 \%)$, uterine exploration $(n=18,12 \%)$ and uterine devascularization $(n=4$, $2.5 \%)$.

Magnesium sulfate $\left(\mathrm{MgSO}_{4}\right)$ was the main anticonvulsant used in eclampsia with additional agents in one-third of them. All of the patients ( $n=126, \sim 80 \%$ of total) received prophylactic antibiotic during caesarean 
Rana et al. Maternal Near-Miss: A Multicenter Surveillance in Kathmandu Valley

section/intervention/procedure and therapeutic antibiotics in all surgical interventions and pregnancy related infection ( $n=132,84 \%$ of total).

The main reasons for women to be categorized as nearmiss in this study were obstetric hemorrhage, medicosurgical complications, hypertensive disorders, abortive outcome, and treatment complications (Table 7). Main contributory factors were mainly anemia $(n=67,43 \%)$ and previous caesarean section $(n=20,13 \%)$.

\begin{tabular}{|ll|}
\hline $\begin{array}{l}\text { Table 7. Reasons for being categorized as near-miss } \\
(>1 \text { condition in 7\%). }\end{array}$ \\
\hline Particulars & $\mathbf{n}(\%)$ \\
Specific Category & $75 \%$ \\
Obstetric hemorrhage & $62(40 \%)$ \\
Hypertensive disorders & $25(16 \%)$ \\
Pregnancy with abortive outcome & $20(13 \%)$ \\
Pregnancy-related infection & $6(4 \%)$ \\
Miscellaneous Category & $25 \%$ \\
$\begin{array}{l}\text { Medical or surgical complication } \\
\text { Unanticipated complications of } \\
\text { management }\end{array}$ & $32(20 \%)$ \\
$\begin{array}{l}\text { Other obstetric disease or } \\
\text { complication }\end{array}$ & $8(17 \%)$ \\
\hline
\end{tabular}

Time to intervention and referral process: Delivery or abortion occurring before arrival and delivery within three hours of arrival at health facility was similar in frequency by $19 \%(n=30)$ and $20 \% \quad(n=31)$ respectively. All women $(n=18)$ requiring laparotomy underwent surgery within three hours. Forty-two (27\%) were referred amongst health facilities due to various reasons and $16(10 \%)$ from low level health facilities.

\section{DISCUSSION}

The facility level indices of severe maternal outcome seemed to be better than expected in developing country. Its rate of $4.4 / 1000$ falls towards lower limit of expected (3-15) per thousand live births. ${ }^{1}$ For every maternal death there are six near-misses. This much of burden was much less than other studies from Syria (60:1) and Iraq (9:1). ${ }^{17,18}$ Low at MMR, high level care (62 vs. 229) indicated obvious need of expanding obstetric care services to countryside.

Severe complications: This multicenter study demonstrated a similar trend of morbid conditions as shown by previous national surveys in Nepal. ${ }^{6}$ Postpartum hemorrhage $(40 \%, n=62)$ and hypertensive disorders of pregnancy $(17 \%, n=25)$ were both the major causes of life threatening conditions as well as the common presentations to characterize the nearmiss. It complied with the desirable number of at least
20 cases with severe maternal outcomes and the nearmiss rate to validate the data. ${ }^{1}$ Some of the medical and surgical conditions to be in the top list could be due to the study location at referral centers. Thus it presumably reflected the community morbidity as well.

Every study has shown hemorrhage and hypertensive complications as the top two causes of near-miss. Studies and reviews of near-miss in developing countries like Syria, Iraq, Indonesia, sub-Saharan Africa, Nigeria and Pakistan yielded similar result. ${ }^{14,17-21}$

Critical interventions, end of pregnancy and management of PPH: In contrast to developed world where blood is most frequently used in surgical procedures or to treat advanced medical diseases such as chemotherapyrelated anemia, obstetric complications are the leading indication for transfusion in developing world. ${ }^{22}$ Obviously hemorrhage would be the primary target to intervene. Half to two-third cases are receiving blood or blood product transfusion everywhere as in this study ( $n=102,65 \%)$. Similarly one-third to half of the cases get admitted elsewhere for intensive care against more than half $(n=85,54 \%)$ in this study, that is within recommended standard of care (30-70\%). ${ }^{1}$ These studies can be considered to validate the reliability of test scale as well.

About two-thirds received surgical intervention including cesarean section. Half of early pregnancy had major surgery and $70 \%$ of late pregnancy had operative intervention but losing a quarter of birth and another $1 / 10^{\text {th }}$ by a week. On top of defined morbid conditions, mean borderline maturity ( $<34$ weeks) also aggravated the fetal/neonatal status.

Oxytocin remained the main medical agent of prophylactic $(n=104,66 \%)$ as well as therapeutic ( $n=92,59 \%$ ) intervention for PPH with other additional oxytocic in around a half or less of those cases amongst all near-miss events. Surgical treatment of $\mathrm{PPH}$ was uterine conservative procedure in $30 \%$ namely compression suture, uterine/abdominal packing, intrauterine balloon tamponade and uterine exploration. Unfeasible (some ruptured uterus) and refractory cases $(13 \%)$ underwent cesarean hysterectomy.

Contributory factors observed were mainly anemia $(43 \%, n=67)$, previous caesarean section (13\%, $\mathrm{n}=20)$, prolonged/obstructed labor $(2.5 \%, \mathrm{n}=4)$ and miscellaneous conditions $(19 \%, n=29)$.

Organ dysfunction: Use of organ dysfunction-based approach to characterize near-miss is well feasible in the sentinel units. ${ }^{4,23}$ Sixty percent of total cases with organ dysfunction were either affected on arrival or within 12 hours in health facility consisting of five percent with 
multi-organ dysfunction. This figure hardly justifies a 12 hour cut-off because $40 \%$ is still a quite large burden beyond this point. Type of organ failure was similar all over. By occurrence the uterine dysfunction was the most frequent event followed by almost equal contribution of hematologic, cardiovascular and respiratory system scoring $84 \%$ altogether. Hepatorenal dysfunction was found only in six percent that has not been found as a common complication in other studies. $^{14-21}$

Standard of care and process indicators: With respect to late pregnancy outcome oxytocin was administered in $86 \%$ (104 in 121) for prevention and $76 \%$ (92 in 121) for treatment of PPH. Adjusting $19 \%$ of cases who arrived after delivery or abortion, every one received oxytocin at health facility. All of the cesarean section received oxytocin as well as prophylactic antibiotics as per hospital protocol. All pregnancy-related infections were treated with intravenous antibiotics. All women with eclampsia received $\mathrm{MgSO}_{4}$. Half of the pregnancy events like delivery and abortion and $100 \%$ of laparotomies occurred within three hours of arrival. Thus these higher proportions of measurable standard of care indicate better quality of care based on WHO guideline at all facilities. ${ }^{1}$

Near-miss criteria: Three-fourth of cases was characterized as near-miss by single pathophysiologic conditions such as obstetric hemorrhage ( 40\%), hypertensive disorder (16\%), abortive outcome (13\%) and infection $(6 \%)$. Out of three approaches for use as a quality of care tool to identify maternal near-miss cases, the WHO Working Group suggests that the organ dysfunction-based approach is the most promising frame for establishing a standard set of criteria. Although this approach would ideally rely on a minimum standard of critical care, including laboratory investigations, clinical criteria alone that is related to a specific disease entity, could be used to identify severe organ dysfunction in resource limited settings. Third one is the interventionbased. ${ }^{4}$ Considering the level of quality of care, single and/or combination of all three criteria has been used in this study.

\section{CONCLUSIONS}

Near-miss condition has similar pattern in many of the studies all over the world. Our study results fell within the standard of care defined by $\mathrm{WHO}$ and yielded the same near-miss conditions as the causes of maternal death reported by national statistics. Obstetric hemorrhage, hypertensive disease of pregnancy, infection, ruptured uterus and heart disease were the common complications in this order as the near-miss events. Detection and management of near-miss as a surrogate event may help reduce maternal death towards achieving MDG. Identification of near-miss event will serve as a surrogate marker of maternal death for the health service planner and provides a window for system level intervention.

\section{ACKNOWLEDGEMENTS}

Researchers acknowledge the participant hospitals and focal persons at different hospitals namely $\mathrm{Dr}$ Aruna Karki, Dr Hema Kumari Pradhan (Kathmandu Model Hospital, Pradarsani Marg); Dr Heera Tuladhar, Dr Bandana Sharma (Kist Medical College, Imadol); Dr Suman Raj Tamrakar (Kathmandu University Medical School, Dhulikhel); Dr Junu Shrestha (Kathmandu Medical College, Sinamangal); Dr Pramila Pradhan, Dr Veena R Shrivastava (Nepal Medical College, Jorpati); Dr Sheela Verma, Dr Madhu Shrestha (Paropakar Maternity and Women's Hospital, Thapathali); Dr Paban Sharma, Dr Alka Singh (Patan Academy of Health Sciences, Lagankhel); Dr Neelam Pradhan, Dr Suniti Rawal (TU Teaching Hospital, Maharajganj); Dr Sudha Thapa, Dr Indira Satyal (Valley Maternity Home, Putalisadak); Mr Sushan Man Shrestha, Dr Archana Amatya and Nepal Society of Obstetricians and Gynecologists (NESOG) executive members.

\section{FINANCIAL SUPPORT}

This study is funded by The International Federation of Gynecologists and Obstetricians (FIGO). It is one of the professional activities directed by annual plan of the FIGO-LOGIC. Researchers and focal persons worked voluntarily on behalf of NESOG. NESOG is a member association of FIGO. FIGO-LOGIC is supporting NESOG's activity on Maternal Neonatal Health in Nepal.

\section{REFERENCES}

1. Evaluating the quality of care for severe pregnancy complications: the WHO near-miss approach for maternal health. Geneva: World Health Organization; 2011.

2. Oladapo OT, Olalekan O, Adetoro OO, Fakeye O, Ekele BA, Adeniran $\mathrm{O}$, et al. National data system on near-miss and maternal death: shifting from maternal risk to public health impact in Nigeria. Reproductive Health. 2009;6:8.

3. Koblinsky M, Chowdhury ME, Moran A, Ronsmans C Maternal morbidity and disability and their consequences: neglected agenda in maternal health. J Health Popul Nutr. 2012 Jun;30(2):124-30.

4. Campbell E, Barrett J. Comprehensive textbook of postpartum hemorrhage. Maternal morbidity and near misses: determining the real numbers. 2e, 2012. 
5. Souza JP, Cecatti JG, Parpinelli MA, Serruya SJ, Amaral E. Appropriate criteria for identification of near-miss maternal morbidity in tertiary care facilities: a cross sectional study. BMC Pregnancy and Childbirth. 2007;7:20.

6. Mantel GD, Buchmann E, Rees H, Pattinson RC. Severe acute maternal morbidity: a pilot study of a definition for a near-miss. Br J Obstet Gynaecol. 1998; 105:985-90.

7. Nepal maternal mortality and morbidity study 2008/9. Kathmandu: Family Health Division, Government of Nepal; 2010.

8. Allen VM, Campbell M, Carson G, Fraser W, Liston RM, Walker M, et al. Maternal mortality and severe maternal morbidity surveillance in Canada. J Obstet Gynaecol Can. 2010;32(12):1140-6.

9. Souza JP, Cecatti JG, Haddad SM, Parpinelli MA, Costa ML, Katz L. Validation of the WHO maternal near-miss approach. PLOS ONE. 2012 Aug;7(8):e44129.

10. Pattinson RC, Buchmann E, Mantel G, Schoon M, Rees H. Can enquiries into severe acute maternal morbidity act as a surrogate for maternal death enquiries? BJOG. 2003;110:889-93.

11. Camargo RS, Pacagnella RC, Cecatti JG, Parpinelli MA, Souza JP, Sousa MH. Subsequent reproductive outcome in women who have experienced a potentially life-threatening condition or a maternal near-miss during pregnancy. CLINICS. 2011;66(8):1367-72.

12. Pattinson RC and Hall M. Near misses: a useful adjunct to maternal death enquiries. British Medical Bulletin. 2003;67:231-43.

13. Cochet L, Pattinson RC, MacDonald AP. Severe acute maternal morbidity and maternal death audit: a rapid diagnostic tool for evaluating maternal care. S Afr Med J. 2003;93:700-2.
14. Nepal Demographic and Health Survey (2011). Kathmandu: Ministry of Health and Population Nepal; 2012.

15. Nepal Millennium Development Goals: Progress Report 2010. Kathmandu: Government of Nepal; 2010.

16. Kaye DK, Kakaire O, Osinde MO. Systematic review of the magnitude and case fatality ratio for severe maternal morbidity in sub-Saharan Africa between 1995 and 2010. BMC Pregnancy and Childbirth. 2011;11:65.

17. Almerie $Y$, Almerie MQ, Matar HE, Shahrour Y, Chamat AA, Abdulsalam A. Obstetric near-miss and maternal mortality in maternity university hospital, Damascus, Syria: a retrospective study. BMC Pregnancy Childbirth. 2010;10:65.

18. Jabir M, Imad AS, Dhikra MS, Wafa AH, Sana AH, Amal $\mathrm{AZ}$, et al. Maternal near-miss and quality of maternal health care in Baghdad, Iraq. BMC Pregnancy and Childbirth. 2013;13:11.

19. Adisasmita A, Deviany PE, Nandiaty F, Stanton C, Ronsmans C. Obstetric near-miss and deaths in public and private hospitals in Indonesia. BMC Pregnancy Childbirth. 2008;8:10.

20. Oladapo OT, Adewale SO, Olatunji AO, Daniel OJ. Near-miss obstetric events and maternal deaths in Sagamu, Nigeria: a retrospective study. Reproductive Health. 2005;2:9.

21. Mustafa R, Hashmi H. Near-miss obstetrical events and maternal deaths. J Coll Physicians Surg Pak. 2009 Dec; 19(12):781-5.

22. Julianna SD, Nour NM. The use of blood in obstetrics and gynecology in the developing world. Rev Obstet Gynecol. 2011;4(2):86-91.

23. Cecatti JG, Souza JP, Neto AF, Parpinelli MA, Sousa MH, Say $\mathrm{L}$, et al. Pre-validation of the WHO organ dysfunction based criteria for identification of maternal near miss. Reproductive Health. 2011;8:22. 